Review

\title{
A snapshot on COVID-19: A review
}

\author{
Mahfuz Al Mamun ${ }^{1}$, Kaiissar Mannoor ${ }^{2 *}$, Tahmina Shirin' ${ }^{3}$, Meerjady Sabrina Flora ${ }^{3}$, Firdausi \\ Qadri $^{2}$ and Li-Li Ren ${ }^{4} \&$ Jianwei Wang ${ }^{4}$
}

1 Translational Research Institute, Henan Provincial People's Hospital, School of Medicine, Henan University, Zhengzhou 450053 and China;

2 Laboratory of Infectious Disease, Institute for developing Science and Health initiatives (ideSHi), Dhaka-1212, Bangladesh;

3 Institute of Epidemiology, Disease Control \& Research (IEDCR), Dhaka-1212, Bangladesh;

4 National Health Commission of the People's Republic of China, Key Laboratory of Systems Biology of Pathogens and Christophe Mérieux Laboratory, Institute of Pathogen Biology, Chinese Academy of Medical Sciences \& Peking Union Medical College, Beijing 100730, China.

* Correspondence: kaiissar@ideshi.org; Tel.: +88-01797440713

Received: date; Accepted: date; Published: date

\begin{abstract}
The emergence of novel SARS-CoV-2 virus in China in December 2019 has turned into a global pandemic through continued spread beyond borders. This review was aimed to extract up-to-date information on the evolution, transmission, clinical manifestations, diagnosis, treatment and prevention of COVID-19 to fight against this common enemy. PubMed, Scopus and Google Scholar were the sources of literature; whereas CDC, WHO and Worldometer provided updated information. Bats served as the reservoirs of this virus while pangolin is believed as an intermediate host to transmit the virus to humans. Direct human-to-human and indirect transmissions were involved. Major clinical manifestations included fever, cough, fatigue, sputum production and shortness of breath. Chest radiographs mostly showed bilateral ground-glass opacities. Aged patients and patients with comorbidities had higher case fatality ratios. Critical cases were vulnerable to develop pneumonia, multi-organ failure and deaths. Overall situation in China has improved substantially. The European region and region of the Americas were the worst hit out of six WHO global regions. PCR based methods are used for the diagnosis of COVID-19. Severe/critical cases essentially require supportive or intensive cares. Avoiding exposure to COVID-19 is the best way to prevent the disease. Thus, this review provides a snapshot on COVID-19.
\end{abstract}

Keywords: COVID-19; SARS-CoV-2; origin; transmission; epidemiology; signs and symptoms; diagnosis; treatment and prevention.

\section{Introduction}

The world has been facing a great crisis due to the emergence and pandemic spread of the novel coronavirus SARS-CoV-2 (Severe acute respiratory syndrome-coronavirus-2) since December 2019. The disease caused by the virus is termed as coronavirus disease 2019 (COVID-19) by the World Health Organization (WHO)[1-4]. The disease has spread across 213 countries or territories with around 2 million infections and over 124,000 deaths globally until April 152020 [5].

\section{Methods}

\subsection{Search Strategy}

PubMed, Scopus and Google Scholar were the sources of literature searching up to April 15 2020; whereas CDC, WHO and Worldometer offered up-to-date data, statistics and health-related information about COVID-19. Search terms included COVID-19 or SARS-CoV-2 or 2019-nCoV or 
novel coronavirus 2019, origin/evolution, transmission, epidemiology, signs and symptoms, diagnostics, and treatment and prevention.

\subsection{Selection criteria}

The references of selected original articles, reviews, perspectives, meta-analyses, reports, and guidelines were manually searched. For data mining and literature review, only those articles or published reports or statistics were taken into consideration that had been subjected to diagnosis of COVID-19 by RT-PCR or gene sequencing, or RT-PCR followed by chest computed tomography (CT) scans. All the authors enlisted herein mutually agreed upon the handpicked articles or reports for analysis during the preparation of the manuscript. Prominence was given to contemplation of information for commoners as well as for general medical readers.

\section{Origin and evolutionary genomics}

SARS-CoV-2, a single-stranded RNA virus belonging to highly infectious beta-coronaviruses has a genome size of 26 to 32 kilobases [6]. Recent genome sequencing revealed bats as the possible natural reservoir of this novel virus since it contains considerable genome homology with coronaviruses of bat origin (bat-CoVs) [7-10]. In China, more than 500 coronaviruses were identified in bats. Human exposure to bat-CoVs might be common among the rural Chinese who live in close contact with the natural habitats of bats what is accounted for $2.9 \%$ bat-CoV seroprevalence in rural China [11]. Phylogenetic analysis demonstrated that COVID-19 shared 88\% sequence identity with two bat-derived SARS-like coronaviruses, namely bat-SL-CoVZC45 and bat-SL-CoVZXC21 [9]. It also shared 96\% homology at the whole genome level to another bat coronavirus RaTG13 [8]. These findings indicated bats as possible reservoir of COVID-19 virus (Figure 1).

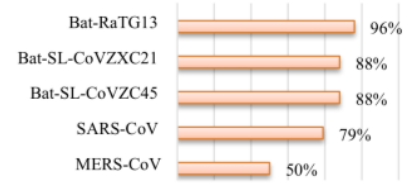

Figure 1. Comparative genomics of novel SARS-CoV-2 virus.

The novel SARS-CoV-2 virus is closely related to bat origin virus RaTG13 while it is distantly related to two commonly known beta-coronaviruses: MERS-CoV and SARS-CoV.

Evolutionary genomics of ORF1a/1b, S (spike) and N (nucleocapsid) genes in COVID-19 revealed it as a recently evolved novel coronavirus [12,13]. An important question yet to be answered whether COVID-19 is directly transmitted to humans from bats or via an intermediary host to humans. The understanding of this clue will clarify the zoonotic pattern of transmission of COVID-19. Bats have come to known as natural reservoirs for SARS-CoV and MERS-CoV (middle east respiratory syndrome coronavirus) outbreaks, where the former and the latter viruses jumped to infect people via civets and camels, respectively [10,14-15]. It was, therefore, hypothesized that like SARS-CoV and MERS-CoV, bats in Wuhan seafood market might have infected a live animal from where the COVID-19 virus could make its way to humans. There is a $99 \%$ genetic homology, particularly in the receptor-binding domains of the $S$ protein gene between the coronaviruses circulating in pangolins and humans. These findings indicated that pangolins might have been the likely intermediate host for COVID-19 transmission to humans (Figure 2) [16,17]. Further research and evidence are needed to pinpoint the intermediary host in order to prevent zoonotic transmission.

\section{Transmission}

Direct human-to-human transmission of COVID-19 virus via inhalation of respiratory droplets from coughing and sneezing of infected patients was confirmed in the epidemic in China (Figure 2) [18-20]. This sort of transmission occurs between people of close contact with a distance of 1.8 meter or 6 feet [20]. COVID-19 virus from respiratory droplets emitted during uncovered coughing or sneezing can also travel up to 15 feet to 27 feet $[97,98]$. The novel coronavirus also spread via contact 
and aerosol transmission. Physical contact involves transmission upon touching a surface tainted with respiratory droplets containing the virus through subsequent contact with mouth, nose or eyes of an uninfected individual. Aerosol transmission occurs upon inhalation of air contaminated with tainted respiratory droplets from infected individuals $[18,21]$.

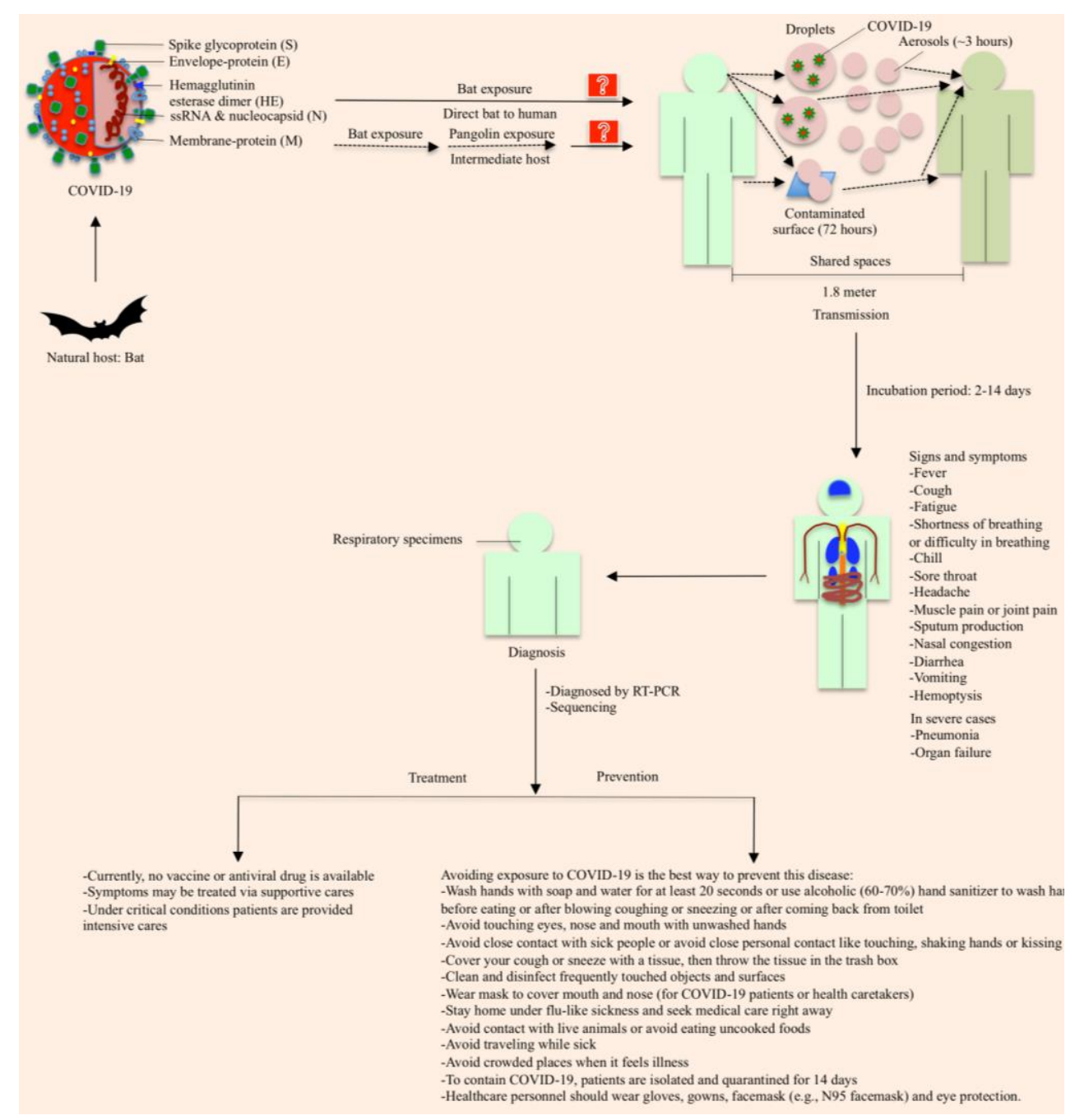

Figure 2. A snapshot on COVID-19.

Bats served as the original host of COVID-19 while pangolin is suspected to be an intermediate host. SARC-CoV-2 is a single stranded RNA (ssRNA) virus mainly consisting of spike glycoprotein (S), envelop protein (E), hemagglutinin esterase $(\mathrm{HE})$, nucleocapsid $(\mathrm{N})$ and membrane protein $(\mathrm{M})$. Human to human transmission was confirmed via droplets or aerosols from coughing or sneezing or via contaminated surfaces by the infected patients. The clinical presentations appearing upon 2-14 days post-infection included fever, fatigue, dry cough, sputum production, shortness of breath/difficulty in breathing, chills, muscle pain, nasal congestion, diarrhea, vomiting and hemoptysis. Under critical or severe conditions it causes pneumonia, organ damage and death. RT-PCR is used to diagnose COVID-19 from respiratory samples of an infected patient. No vaccine or anti-viral drug has approved yet; hence, supportive/intensive cares should be taken into consideration.

Recently, it has been reported that SARS-CoV-2 remains viable for around 3 hours to 3 days in aerosols, on copper surface for 4 hours, 1 day on cardboard, and three hours on inanimate surfaces like plastics and stainless steel; thus, indicating aerosol and fomite modes of COVID-19 transmission [22]. Is COVID-19 airborne? Evidence disclosed no existence of SARS-CoV-2 viral RNA in air samples in closed settings where infected patients had been admitted [106]. However, the presence of viral RNA in air does not represent its transmissibility or infectivity. Currently, information on how long the virus persists in locally or internationally traded foods or raw food materials as well as the potential role of food in the transmission of the virus remains unexplored. Certain atmospheric parameters such as temperature, humidity and light should be taken into consideration for 
conducting investigations since these may play prominent roles in viral transmission. In general, coronaviruses are thermolabile and their persistence appears to be stable at low temperatures including the freezing temperatures. The SARS-CoV are very stable in a frozen state and can survive for up to two years at $-20^{\circ} \mathrm{C}$ [5]. Studies on coronaviruses like SARS-CoV and MERS-CoV, for example, revealed that they could persist on surfaces in infectious state for a couple of hours to nine days at room temperature and their lifespan is further increased when low temperature is associated with high air humidity [23]. These findings may be translated into practice for prevention of COVID-19 transmission. Controversial findings reported the potential risks of vertical transmission of COVID-19 from pregnant- and breast-feeding women [24-26]. Possibility of fecal-oral transmission of COVID-19 was also demonstrated by one study [27].

SARS-CoV-2 has higher reproductive number $\left(\mathrm{R}_{0}\right)$ than SARS-CoV-1 and influenza virus. For COVID-19 epidemic in Wuhan, $\mathrm{R}_{0}$ was estimated to be roughly 2.68 meaning that on an average each patient had potential of spreading the infections to 2.68 people [28]. Several studies reported $R_{0}$ in the range from 1.4 to 6.49 with a mean of 3.28 [29]. The COVID-19 pandemic will keep on increasing as long as $R_{0}$ is greater than 1 . Therefore, to prevent the disease from spreading, control measures are needed to reduce the reproductive number to less than 1. In spite of the fact that COVID-19 appears to have more transmission potential than SARS CoV or MERS CoV and $\mathrm{R}_{0}$ of many estimates of COVID-19 have already been published, until now it is too early to calculate an accurate $\mathrm{R}_{0}$ estimate to assess the transmission dynamics. One of the most difficult aspects of $\mathrm{R}_{0}$ of beta-coronaviruses has been the circumstance under which the virus is transmitted to a large proportion of people leading to superspreading, a pivotal event for global spread of the disease, which deals with transmission of infections to at least eight contacts [30]. So-called superspreading events occurred in the global spread of SARS to Hong Kong, Beijing and Singapore [30-32]. Superspreading events were reported in SARS-CoV-2 outbreaks on Diamond Princess cruise ship where initial $\mathrm{R}_{0}$ was 14.6, which was four times higher than initial $\mathrm{R}_{0}$ of disease epicenter in Wuhan [99]. The superspreading events are influenced by many factors like host-pathogen relationship, environment, preventative measures and health care facilities, behavioral and hygiene practices, virulence of a newly emerged virus, environmental persistence and population density [100]. After implementation of disease control measures like isolation and quarantine, the $R_{0}$ became lowered to 1.78 on the cruise ship [100]. In a question concerning to $2019-\mathrm{nCoV}$ if it acts as superspreaders, a group of Japanese scientists reported that closed environment promoted superspreading events. The study reported that COVID-19 transmission was 18.7 times higher in a closed environment than an open-air environment [101]. In SARS-CoV, the spike protein (S) plays a critical role for cross-species and human-to-human transmission. Structural analysis of COVID-19 S-protein has shown that its binding affinity to human ACE2 (angiotensin-converting enzyme 2) receptor was stronger than that for the 2003 strain of SARS-CoV, indicating the tremendous host interaction potential of COVID-19 virus [33,34]. Could the COVID-19 virus mutate to be more infectious to spread? Preliminary study suggested that SARS-CoV-2 had two genetic subtypes designated as L and S. Although $S$ was ancestral in origin, the L subtype was more prevalent in Wuhan (disease epicenter) and hypothesized to be more aggressive and quick-spreader under human interventions [102].

Question may arise if asymptomatic patients can act as a major driver of transmission. A recent study has reported asymptomatic persons as potential sources of COVID-19 infections pointing towards reassessment of transmission dynamics of the current outbreak [35]. Information on the proportion of truly asymptomatic infections seems to be lower [36] and superspreading events are not related to asymptomatic mode of transmission [100]. High viral loads of COVID-19 were found within the first few days after onset of the symptoms and the presence of viral RNA can be prolonged up to 24 days [37]. Even longer duration of viral shedding had been reported [38]. Towards the end of this period of viral presence, viruses were detected at irregular intervals from nasopharyngeal aspirates. It is crucial to determine if COVID-19 remains transmissible throughout the period of detectability that certainly will contribute towards control measures. Thus, multiple 
shedding routes can be attributed to the high contagiousness and infectivity of the newly emerged virus (Figure 2).

\section{Epidemiological parameters and clinical manifestations}

Upon exposure to COVID-19, symptoms may appear in as few as 2 days or as long as 14 days. Also, infected persons may be asymptomatic [38]. Studies estimated a median incubation period of COVID-19 (time between infections and onset of symptoms) to be 5-6 days in the range of 0-14 days [39-45]. The common clinical manifestations included fever, cough, shortness of breath, myalgia, fatigue and bilateral lung with ground-glass opacity while less common or infrequent symptoms are headache, sore throat, rhinorrhea (runny nose), chest pain, upper airway congestion, diarrhea, hemoptysis, arthralgia, nausea and vomiting [43,46-54]. The clinical features including fever, dry cough, shortness of breath, and bilateral ground-glass opacities displayed resemblance to SARS-CoV and MERS-CoV infections to some extent [55,65]. Radiographs on 81 patients with COVID-19 pneumonia revealed bilateral (64 [79\%] patients), peripheral (44 [54\%]), poorly defined (66 [81\%]), and ground-glass opacification (53 [65\%]) [54]. In critical conditions, COVID-19 can lead to severe pneumonia, multi-organ dysfunctions and deaths [43,46-54]. The 'WHO-China Joint Mission on COVID-19' described the clinical and epidemiological features, outcomes and laboratory findings of 55,924 laboratory-confirmed cases in China [36]. According to this report, typical clinical features included fever $(87.9 \%)$ [n=49,157], dry cough $(67.7 \%)$ [n=37,860], weakness $(38.1 \%)[n=21,307]$, sputum production (33.4\%) [n=18678], dyspnea (18.6\%) [n=10,402], throat pain $(13.9 \%)[n=7,773]$, headache $(13.6 \%)$ [n=7,605], muscle pain or joint pain $(14.8 \%)$ [n=7,605], chills $(11.4 \%)$ [n=6375], nausea or vomiting $(5.0 \%)$ [2,796], nasal congestion $(4.8 \%)$ [n=2684], diarrhea $(3.7 \%)[=2069]$, and the coughing up of blood $(0.9 \%)$ [503], and conjunctival congestion $(0.8 \%)$ [n=447] (Figure 3A). Frequency of these clinical features significantly differed from the recently reported statistics of European Surveillance System (TESSy) on 14,011 cases from 13 countries in terms of fever [6585(47\%)], productive or dry cough [3503(25\%)], sore throat [2242(16\%)], fatigue [841(6\%)] and pain [701(5\%)] [103]. The joint report also showed that 80\% COVID-19 patients had mild symptoms, $14 \%$ had severe disease manifestations and 6\% developed critical conditions (Figure 3B). Patients having underlying comorbidities such as hypertension, diabetes, cardiovascular disease, chronic respiratory disease and cancer showed susceptibility to develop critical signs and symptoms (Figure 3C). On the other hand, although a large proportion of under-19 children were asymptomatic, some developed mild symptoms while only $0.2 \%$ developed severe and critical disease (Figure 3D) [36,57]. Patients with severe and critical conditions were usually among the aged people (>60 years) (Figure 3D). Like MERS-CoV and SARS-CoV, males (CFR 4.7\%) were more susceptible to get infected with COVID-19 than females (CFR 2.8\%) [36,58-59]. Overall epidemiological scenario in China improved substantially with a significant decrease in new cases and deaths from December 312019 through April 152020 (Figure 3E).

Rapid explosion of COVID-19 cases and deaths were reported in European countries. Globally 51\% [ $n=977,596]$ COVID-19 cases and 69\% [n= 84,607] deaths were recorded solely in European Region since December 312019 through April 152020 among WHO six global regions of COVID-19 pandemic (European Region, Western Pacific Region, Eastern Mediterranean Region, South East Asia Region, Africa Region and Region of the Americas). After the European Region, the Region of the Americas was worst affected with $35 \%$ infected cases $[n=673,361]$ and $22 \%$ deaths $[n=27,336]$ (Figure 4A \& 4B). Overall situations of the five European countries, namely, Italy, Spain, France, Germany and UK, one Middle East country (e.g., Iran), and one region of the America (e.g., USA) were rapidly deteriorating in the context of new cases and deaths at the time of writing this manuscript (Figure 4C-4D) [5]. The crude CFRs of Italy, Spain, France and UK were over 10\% (Figure 4E). As of April 16, 2020 there were 24.5\% [n=510,666] recovery, 66.6\% mild cases [ $n=1,387,165], 2.5 \%$ critical cases $[n=51,144]$ and $6.5 \%$ deaths $[n=134,632]$ caused by COVID-19 infections. (https://www.worldometers.info/coronavirus/) (Figure 4F). From December 312020 through April 
15 2020, the overall global situations were gradually worsening in terms of cumulative cases and deaths (https://www.who.int, COVID-19: situation-reports) (Figure 4G).
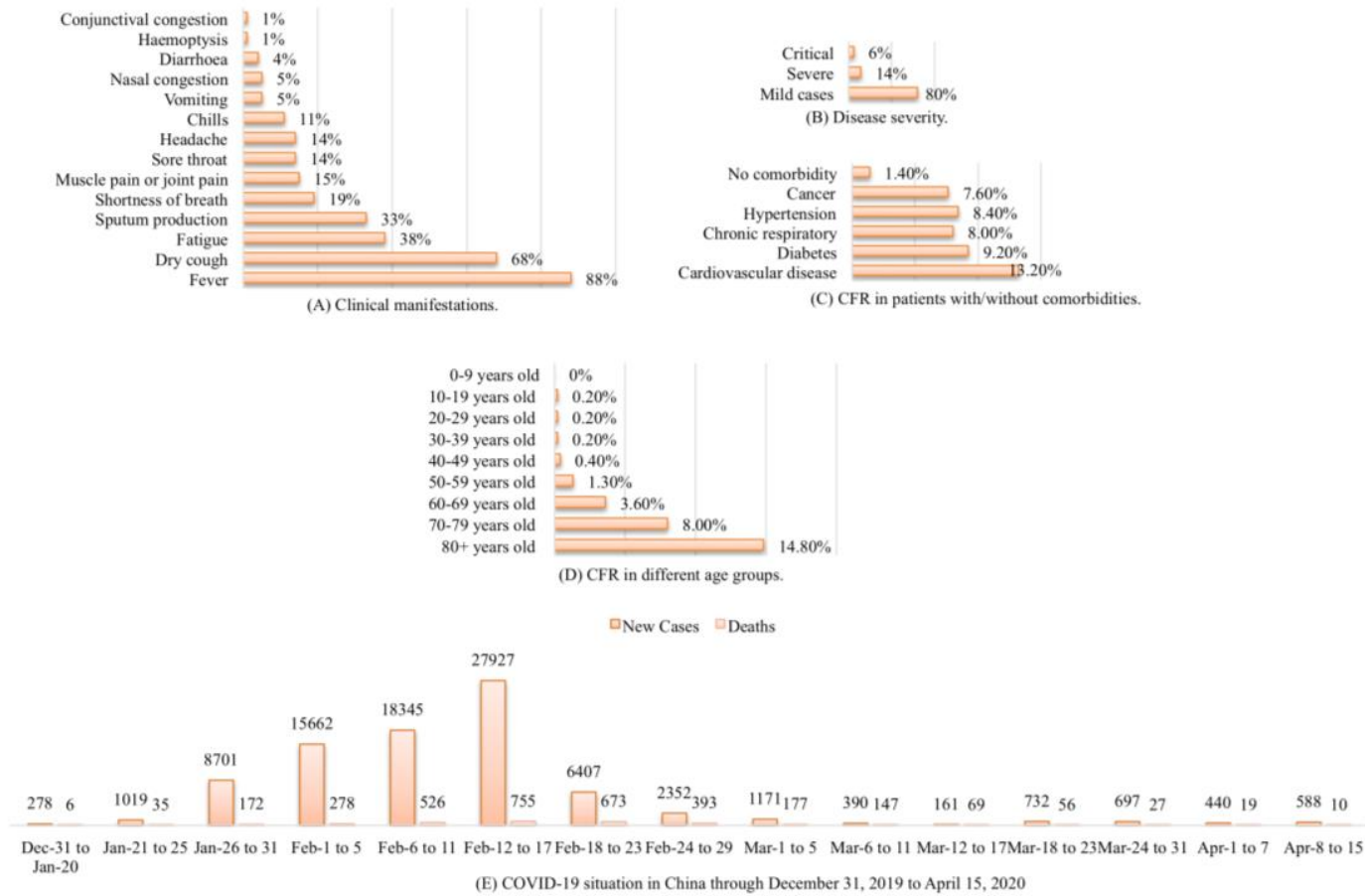

Figure 3. Clinical and epidemiological features of COVID-19 in China.

(A) Clinical presentations included fever, fatigue, dry cough, sputum production, shortness of breath, muscle or joint pains, sore throat, headache, chills, muscle/joint pain, shortness of breath, sputum production, vomiting, nasal congestion, diarrhea, hemoptysis and conjunctival congestion. (B) Most of the cases were mild. (C) Case fatality ratios (CFRs) were higher in the patients with comorbidities compared to the patients without comorbidities. (D) CFRs trend to be higher in old people aged over 60. (E) The representative graph of COVID-19 situations in China through December 312019 to April 152020 revealed that it had peaked in mid-February and started declining in late February 2020.

By the time the global SARS outbreak was contained, there were 774 deaths with an overall CFR of $9.6 \%$ among 8096 SARS cases across 29 countries, whereas MERS CoV was not contained yet and responsible for 858 deaths with a CFR of $34.4 \%$ among 2494 confirmed cases across 27 countries [60]. Regardless of much higher CFRs for SARS and MERS, COVID-19 had caused more total deaths owing to the large number of infected cases. Since the outbreak keeps continuing, CFR may change; hence, it is too early to estimate global CFR for COVID-19. In addition to CFR and incubation period, certain key epidemiological parameters including infection fatality ratio (IFR, the portion of all infected cases who die) and the serial interval (SI, the time between the onset of symptoms of a primary and secondary case) could be taken into consideration in order to minimize the global spread and contain COVID-19. Preliminary estimation showed that COVID-19 had a SI of 4.4 to 7.5 days and the IFR ranged from $0.3 \%$ to $1 \%$ [42,61,62]. IFR needs population-based serologic studies without which it is not possible to estimate the proper ratio of the population infected with COVID-19 at this moment. Updated data is needed to confirm this estimation. Using preliminary data, the Joint Mission demonstrated that the median time from disease onset to clinical recovery for mild cases was around 2 weeks, whereas it was 3-6 weeks for patients with severe or critical illness. On the other hand, the time duration from disease onset to the development of severe illness to fatal outcome was 1 week and 2-8 weeks, respectively.

\section{Diagnosis}

People with epidemiological history of recent travel to the epicenter of COVID-19 outbreaks or residents of any other cities with COVID-19 infected patient(s) or people who have close contact with symptomatic or asymptomatic patients are recommended for diagnosis [63]. The common 
laboratory findings among the hospitalized patients with COVID-19 pneumonia upon admission included leukocytopenia including lymphocytopenia, thrombocytopenia and elevated alanine/aspartate transaminases $[42,47,48]$.

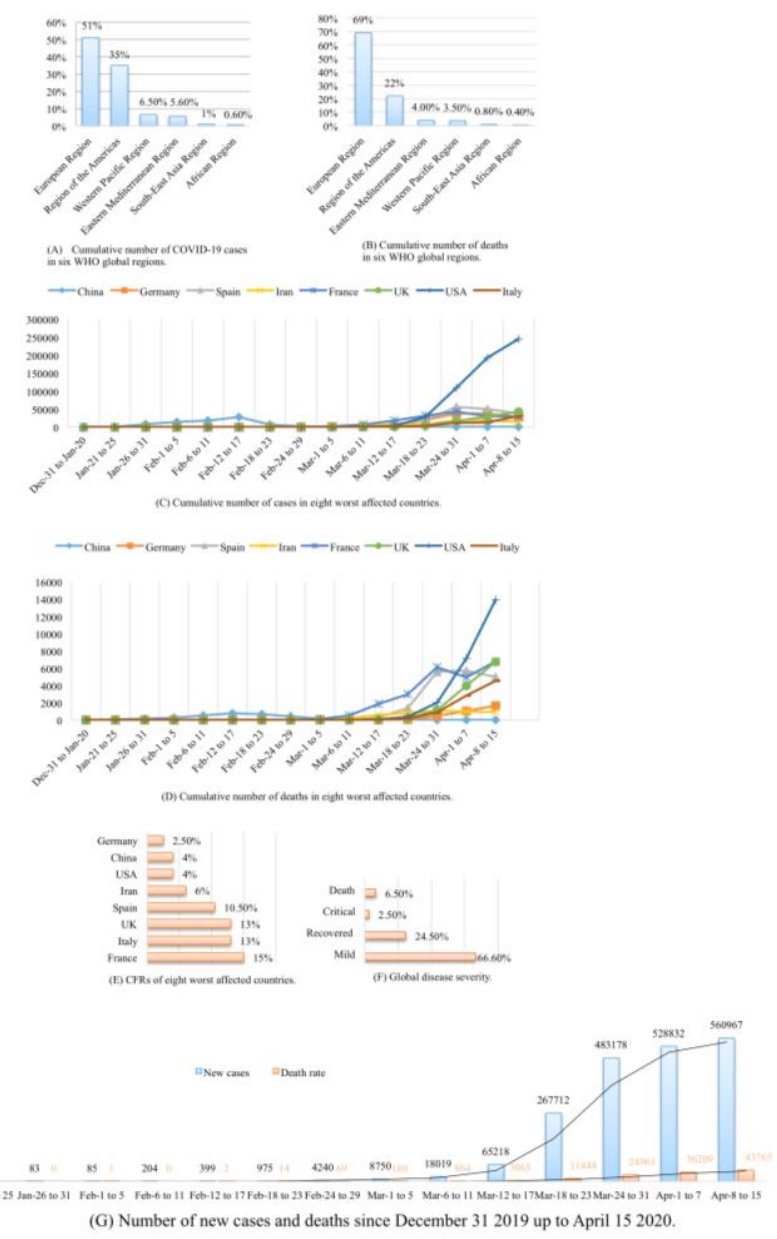

Figure 4. Global situations of COVID-19 pandemic.

(A) \& (B) Cumulative number of COVID-19 cases and deaths were higher in Europe region among six WHO global regions. (C) \& (D) Eight countries were worst hit in terms of new cases and deaths since December 312019 up to April 152020. (E) Dreadful situations in context of new cases and deaths were found in Italy, France, Spain, UK and USA. CFRs were recorded highest in France (15\%) among all eight countries. F. As of April 16, 2020 the global disease severity was characterized by $24.50 \%$ recovery, $66.60 \%$ mild cases, $2.5 \%$ critical or severe cases, and $6.50 \%$ deaths. (G) Numbers of new cases and deaths kept increasing alarmingly globally since December 312019 to April 152020.

Patients with suspected COVID-19 are subjected to screening by preliminary chest CT scan followed by next generation sequencing or RT-PCR for confirmation [54,48]. Chest radiograph of COVID-19 patients had manifestation of bilateral ground-glass opacities. Asymptomatic infections were detected on the basis of CT scan findings in high-risk individuals with a history of exposure to COVID-19 patients. Although CT scan can be used to accelerate early diagnosis, yet CT features seem not to be specific due to having resemblance to those of SARS-CoV and MERS-CoV infections [54,64-65]. In addition, CT scan within 2 days after onset of clinical manifestations revealed that 56\% patients had normal CT findings [66]. However, the whole genome sequencing of SARS-CoV-2 virus by Chinese scientists expedited the development of molecular diagnostics like RT-PCR assay by utilizing novel gene sequence of COVID-19 virus [9,48,67-68]. Although the presence of COVID-19 was detected in blood plasma or stool specimens, CDC recommended upper respiratory samples (e.g., nasopharyngeal swabs, oropharyngeal swabs and nasopharyngeal wash/aspirate) or lower respiratory samples (e.g., sputum, bronchoalveolar lavage and tracheal aspirate) for RT-PCR-based diagnostics $[9,67,69-70]$. Viral loads were reported to be more in respiratory specimens than in stools or bloods $[37,71]$. In MERS, the viral loads were higher in respiratory specimens than in blood and 
stool [72]. How longer the COVID-19 RNA can be identified in respiratory or extra-pulmonary samples remain unexplored. COVID-19 virus was found in specimen culture from stool of infected patients with pneumonia 15 days after onset of symptoms showing possibility of faecal oral transmission [73]. Like MERS-CoV or SARS-CoV, SARS-CoV-2 RNA could be detected for weeks [74-75]. The major drawback of RT-PCR based diagnostic method is that it produces a positive result when viruses are present in the human body. It is not possible to identify people with past infections who cleared the virus from their bodies and back to normal, thus emphasizing the development of serological test to confirm if someone had past infections of COVID-19 virus [76]. It undoubtedly will help to better understand the epidemiology of COVID-19.

\section{Treatments and Prevention}

So far, no vaccine or antiviral drug has been approved for treatment of COVID-19 infections. Multiple attempts had already been made to develop COVID-19 specific vaccine. As of April 11 2020, around 67 candidate vaccines were under preclinical evaluations while 3 vaccines were under clinical evaluations, namely, recombinant adenovirus vaccine (Phase 1 [ChiCTR2000030906, Phase 2 [ChiCTR2000031781]), RNA vaccine (Phase 1 [NCT04283461]), and DNA vaccine (Phase 1 [NCT04336410]) [77]. In relevance to $\mathrm{WHO}$ as it was said that there was less possibility of having vaccine(s) available to people by less than 18 months, since in general, it takes two to five years to develop a vaccine [78].

In the absence of vaccines against COVID-19 or specific antivirals for treating SARS-CoV-2, the hospitalized patients are preliminarily managed through supportive cares with existing antiviral drugs like remdesivir [46,70,79], combination of lopinavir and ritonavir [45-46,80-82], hydrochloroquine [46,79,83], oseltamivir [43,45,53], ganciclovir [43,53], interferon alfa-2b [81] and galidesivir [84]. As of April 14 2020, WHO registered 614 therapeutics for clinical trials [104]. Some of these drugs, e.g., remdesivir, lopinavir/ritonavir, chloroquine, oseltamivir and interferon alfa- $2 b$ had been reported to respond well to SARS-CoV-2 infections, and now they are undergoing clinical trials $[83,85,86]$. In a cohort of severe COVID-19 infections, clinical trials with lopinavir-ritonavir (ChiCTR2000029308) have showed no obvious benefit $(106,87)$. Patients with SARS-CoV-2 pneumonia who developed acute respiratory distress syndrome (ARDS) under critically ill conditions are urgently managed in intensive care unit (ICU) using mechanical ventilation (invasive or non-invasive) and oxygen therapy [43,46-47,53]. However, recently, convalescent plasma therapy in critically ill patients has shown promising recovery from COVID-19 [105]. It needs more randomized clinical trials to take the therapy to grass root levels.

As mentioned earlier, the best way to prevent the disease is to undertake all necessary measures to avoid being exposed to the virus (Figure 2) [88-93]. Because of the highly contagious nature of COVID-19, person with close contacts and suspicious exposure is advised to stay isolated and observe a 14-day long health monitoring starting from the last day of contact with the COVID-19 infected patients or suspicious environmental exposure. Patients displaying symptoms of COVID-19, especially fever, coughing and shortness of breath, should seek medical care immediately. Patients with suspected infection should be isolated, monitored, and diagnosed in hospital setting as soon as possible. International travelers need to take precautions upon entering and leaving the affected areas by way of avoiding close contacts with people with acute respiratory illness, washing hands frequently, and avoiding close contact with live or dead domestic animals, bats or other wild animals. Anyone with travel history to the epicenter of the disease or other COVID-19 affected countries or territories in the past 14 days with onset of fever, cough or difficulty breathing should consult with medical doctor urgently, avoid contact with others; avoid traveling around, cover mouth and nose with mask to contain the spread of viruses, use tissue or sleeve while coughing or sneezing and discard tissues into trash box, and wash hands with soap and water or any disinfectants or alcoholic hand sanitizers for at least 20 seconds. Generally, normal facial masks are 
recommended for the people with suspected or COVID-19 infected patients, and special masks like N95 for their caregivers, but not for the healthy people. After contact with the suspected COVID-19 patients, people should not touch their mouths, noses or eyes with unclean or unwashed hands. After leaving patient's room, one should clean or disinfect one's clothes and hands. We all should wash our hands before and after eating, after using the toilet and after entering house from outside. It is also suggested to avoid direct contact with secretions or discharges (e.g., oral or respiratory discharges, feces) of COVID-19 patients, and avoid hugging or kissing. As of 20 February 2020, 88\% of 2,055 COVID-19 confirmed cases from 476 hospitals across China were from the healthcare workers of Hubei province while only $12 \%$ were from rest of China [36]. Hence, healthcare personnel engaged in patient care services should wear gloves, gowns, facemask (e.g., N95 facemask) and eye protection upon entry into the patient care area. After leaving the patient care area, the engaging healthcare personnel should remove and discard personal protective equipment (PPE), and immediately perform hand hygiene. Healthcare providers must take stringent precautions during performing aerosol-generating procedures that can induce coughing or sneezing (e.g., sputum induction, open suctioning of airways or collection of respiratory specimens for diagnosis, such as nasopharyngeal swab) from the patients with known or suspected COVID-19, and during handling of patient's feces and urine, and in time of changing and cleaning dresses, bed sheets, bath towels, towels, and rooms of the COVID-19 patients. The global number of confirmed cases of COVID-19 keeps on increasing by spreading to new countries and territories. The pandemic can be slowed down or even reversed through implementation of robust community containment and control measures that have already been demonstrated by China and South Korea. To achieve the goal of containment, China has worked across society to identify people who are sick of COVID-19, bringing them to care, following up on contacts, preparing hospitals and clinics to manage a surge of patients for isolation and quarantine, social distancing, and training health professionals [94-96].

\section{Concluding Remarks}

The COVID-19 pandemic is threatening millions of lives and is spreading fast and affecting new countries or territories across the world. All persons regardless of age, sex and race need to follow biosafety guidelines (WHO or CDC guidelines) to minimize exposure to virus or virus-infected patients. All should practice health hygiene like cleaning hands frequently. Infected patients should take utmost care to avoid contact with uninfected individuals and seek advice from the authorized caretakers. Clinicians or healthcare professionals should take appropriate precautions (e.g., personal protective equipment) since they maintain close contact with COVID-19 infected patients. Implementation of personal hygiene approaches towards community containment and control measures is urgently needed to slowdown or to push back the pandemic, which could be achieved by identifying infected people, providing them with care and facilities for isolation and quarantine, social and physical distancing, training health caretakers and clinicians, and by creating awareness of COVID-19 among commoners (Figure 2).

Acknowledgments: We are highly grateful to Prof. Syed Saleheen Qadri, Scientific Co-coordinator of ideSHi for his kind time during preparation of the manuscript.

Funding: KM and FQ were supported by grants from the Institute for Developing Science and Health Initiatives (ideSHi), Dhaka 1212, Bangladesh.

Author contributions: M.A.M.; was involved as first author in planning and writing of the manuscript; F.Q.; T.S.; L.R.; and M.S.F.; provided valuable guidelines, critical comments and intellectual contents during manuscript preparation. J.W.; and K.M.; edited the figures and revised the manuscript. K.M.; was involved as corresponding author.

Conflicts of Interest: The authors declare no conflict of interest. The funders had no role in the design of the study; in the collection, analyses, or interpretation of data; in the writing of the manuscript, or in the decision to publish the results. 


\section{References}

1. WHO. Novel Coronavirus (2019-nCoV): situation report, 22 (PDF). Updated February 11, 2020. https://www.who.int/docs/default-source/coronaviruse/situation-reports/20200211-sitrep-22-ncov.pdf?sfvrsn=f b6d49b1_2.

2. Gorbalenya AE, Baker SC, Baric RS et al. The species severe acute respiratory syndrome-related coronavirus: classifying 2019-nCoV and naming it SARS-CoV-2. Nat. Microbiol. 2020 5, 536-544. https://doi.org/10.1038/s41564-020-0695-z.

3. BBC. Coronavirus disease named Covid-19. BBC News. February 11, 2020.

4. Hui DS, Azhar E, Madani TA, et al. The continuing 2019-nCoV epidemic threat of novel coronaviruses to global health - The latest 2019 novel coronavirus outbreak in Wuhan, China. Int. J. Infect. Dis. 2020, 91, $264-266$. doi:10.1016/j.ijid.2020.01.009. PMID 31953166.

5. WHO. Coronavirus disease 2019 (COVID-19) Situation Report -85. Updated April 15, 2020. https://www.who.int/docs/default-source/coronaviruse/situation-reports/20200415-sitrep-86-covid-19.pdf?sfvr sn=c615ea20_4.

6. Su S, Wong G, Shi W, et al. Epidemiology, genetic recombination, and pathogenesis of coronaviruses. Trends. Microbiol. 2016, 24, 490-502.

7. Zhu N, Zhang D, Wang W, et al. A Novel Coronavirus from Patients with Pneumonia in China, 2019. N. Engl. J. Med. 2020, 382(8), 727-733. doi:10.1056/NEJMoa2001017.

8. Zhou P, Yang X-L, Wang X-G, et al. Discovery of a novel coronavirus associated with the recent pneumonia outbreak in humans and its potential bat origin. Preprint.bioRxiv. Preprint posted January 23, 2020. doi: 10.1038/s41586-020-2012-7.

9. Roujian Lu, Xiang Zhao, Juan Li, et al. Genomic characterisation and epidemiology of 2019 novel coronavirus: implications for virus origins and receptor binding. Lancet. 2020, 395(10224), 565-574. https://doi.org/10.1016/S0140-6736(20)30251-8.

10. Cui J, Li F, \& Shi Z. Origin and evolution of pathogenic coronaviruses. Nat. Rev. Microbiol. 2019, 17:181-192. https://doi.org/10.1038/s41579-018-0118-9.

11. Wang N, Li SY, Yang XL, et al. Serological Evidence of Bat SARS-Related Coronavirus Infection in Humans, China. Virol. Sin. 2018, 33(1), 104-107. doi:10.1007/s12250-018-0012-7.

12. Chen L, Liu W, Zhang Q, et al. RNA based mNGS approach identifies a novel human coronavirus from two individual pneumonia cases in 2019 Wuhan outbreak. Emerg. Microbes. Infect. 2020, 9, 313-19. doi:10.1080/ 22221751.2020.1725399.

13. Ren LL, Wang YM, Wu ZQ, et al. Identification of a novel coronavirus causing severe pneumonia in human:

a descriptive study [published online ahead of print, 2020 Feb 11]. Chin. Med. J. (Engl). 2020. 10.1097/CM9.0000000000000722.doi:10.1097/CM9.0000000000000722.

14. Li X, Song Y, Wong G and Cui J. Bat origin of a new human coronavirus: there and back again. Sci. China. Life. Sci. 2020, 63. https://doi.org/10.1007/s11427-020-1645-7.

15. Yu P, Zheng BH, Shi JL, Cui J. Geographical structure of bat SARS-related coronaviruses. Infection Genetics and Evolution. 2019, 69, 224-229227. https://doi.org/10.1016/j.meegid.2019.02.001.

16. Xiao K, Zhai J, Feng Y, et al. Isolation and Characterization of 2019-nCoV-like Coronavirus from Malayan Pangolins. bioRxiv. Preprint posted on February 17, 2020.. doi:10.1101/2020.02.17.951335.

17. Wahb L, Jain N, Fire AZ, et al. Identification of a pangolin niche for a 2019-nCoV-like coronavirus through an extensive meta-metagenomic search. Preprint posted on February 8, 2020. https://www.biorxiv.org/content/10.1101/2020.02.08.939660v2 (2020). 
18. Chan JFW, Yuan S, Kok KH, et al. A familial cluster of pneumonia associated with the 2019 novel coronavirus indicating person-to-person transmission: a study of a family cluster. Lancet. 2020, 395(10223), 514-523. https://doi.org/10.1016/S0140-6736(20)30154-9.sispep

19. CDC. 2019 Novel Coronavirus (2019-nCoV). Updated on February 11, 2020. https://www.cdc.gov/coronavirus/2019-ncov/index.html.

20. Phan LT, Nguyen TV, Luong QC et al. Importation and Human-to-Human Transmission of a Novel Coronavirus in Vietnam. N. Engl. J. Med. 2020, 382, 872-874.

DOI: 10.1056/NEJMc2001272

21. Wenting Z. Shanghai officials reveal novel coronavirus transmission modes. Updated February 8, 2020. https://www.chinadaily.com.cn/a/202002/08/WS5e3e7d97a310128217275fc3.html.

22. van Doremalen N, Bushmaker T, Morris DH, et al. Aerosol and Surface Stability of SARS-CoV-2 as Compared with SARS-CoV-1 [published online ahead of print, 2020 Mar 17]. N. Engl. J. Med. 2020. doi:10.1056/NEJMc2004973.

23.Kampf G, Todt D, Pfaender S \& Steinmann E. Persistence of coronaviruses on inanimate surfaces and its inactivation with biocidal agents. Journal of Hospital Infection. Journal of Hospital Infection. 2020, 104(3), $246-251$. https://doi.org/10.1016/j.jhin.2020.01.022.

24. Chen H, Guo J, Wang C et al. Clinical characteristics and intrauterine vertical transmission potential of COVID-19 infection in nine pregnant women: a retrospective review of medical records. Lancet. 2020. 395(10226):809-815. https://doi.org/10.1016/S0140-6736(20)30360-3.

25. Zhu H, Wang L, Fang C, et al. Clinical analysis of 10 neonates born to mothers with 2019-nCoV pneumonia. Transl. Pediatr. 2020, 9(1), 51-60. doi:10.21037/tp.2020.02.06.

26. Jie Qiao. What are the risks of COVID-19 infection in pregnant women? Lancet. 2020, 395(10226), 760-762. https://doi.org/10.1016/S0140-6736(20)30365-2.

27. Wei Zhang, Rong-Hui Du, Bei Li et al. Molecular and serological investigation of 2019-nCoV infected patients: implication of multiple shedding routes. Emerging Microbes $\mathcal{E}$ Infections. 2020, 9(1), 386-389. DOI: 10.1080/22221751.2020.1729071.

28. Wu JT, Leung K, Leung GM. Nowcasting and forecasting the potential domestic and international spread of the 2019-nCoV outbreak originating in Wuhan, China: a modelling study. Lancet. 2020, 395(10225), 689-697. https://doi.org/10.1016/S0140-6736(20)30260-9.

29. Liu Y, Gayle AA, Wilder-Smith A, Rocklöv J. The reproductive number of COVID-19 is higher compared to SARS coronavirus. J. Travel Med. 2020, 27(2), taaa021. doi:10.1093/jtm/taaa021.

30. Shen Z, Ning F, Zhou et al. Superspreading SARS Events, Beijing, 2003. Emerg. Infect. Dis. 2004, 10(2), 256-260. https://dx.doi.org/10.3201/eid1002.030732.

31. Liang W, Zhu Z, Guo J, Liu Z, He X, Zhou W. Severe acute respiratory syndrome, Beijing, 2003. Emerg. Infect. Dis. 2004, 10:25-31.

32. CDC. Severe acute respiratory syndrome-Singapore, 2003. MMWR. 2003, 52, 405-11.

33. Wan Y, Shang J, Graham R, Baric RS, Li F. Receptor recognition by novel coronavirus from Wuhan: an analysis based on decade-long structural studies of SARS. Journal of Virology. 2020, 94 (7), e00127-20. DOI: 10.1128/JVI.00127-20.

34. $\mathrm{Xu}$ X, Chen $\mathrm{P}$, Wang J, et al. Evolution of the novel coronavirus from the ongoing Wuhan outbreak and modeling of its spike protein for risk of human transmission. Sci. China Life Sci. 2020, 63. https://doi.org/10.1007/s11427-020-1637-5. 
35. Rothe C, Schunk M, Sothmann P, et al. Transmission of 2019-nCoV Infection from an Asymptomatic Contact in Germany. N. Engl. J. Med. 2020, 382(10), 970-971. doi:10.1056/NEJMc2001468.

36. Report of the WHO-China Joint Mission on Coronavirus Disease 2019 (COVID-19). Updated on February 16-24,

2020. https://www.who.int/docs/default-source/coronaviruse/who-china-joint-mission-on-covid-19-final-report.pdf. 37. Young BE, Ong SWX, Kalimuddin S, et al. Epidemiologic Features and Clinical Course of Patients Infected With SARS-CoV-2 in Singapore [published online ahead of print, 2020 Mar 3]. JAMA. 2020, e203204. doi:10.1001/jama.2020.3204.

38. Zou L, Ruan F, Huang M, et al. SARS-CoV-2 Viral Load in Upper Respiratory Specimens of Infected Patients. N. Engl. J. Med. 2020, 382(12), 1177-1179. doi:10.1056/NEJMc2001737.

39. Liu T, Hu J, Kang M, et al. Transmission dynamics of 2019 novel coronavirus (2019-nCoV). Preprint posted January 26, 2020. doi: https://doi.org/10.1101/2020.01.25.919787.

40. Jantien B, Don K, Jacco W. Incubation period of 2019 novel coronavirus (2019-nCoV) infections among travellers from Wuhan, China, 20-28 January 2020. Euro Surveill. 2020, 25(5):pii=2000062. https://doi.org/10.2807/1560-7917.ES.2020.25.5.2000062.

41. Linton NM, Kobayashi T, Yang Y et al. Incubation Period and Other Epidemiological Characteristics of 2019 Novel Coronavirus Infections with Right Truncation: A Statistical Analysis of Publicly Available Case Data. J. Clin. Med. 2020, 9, 538.

42. Li Q, Guan X, Wu P et al. Early Transmission Dynamics in Wuhan, China, of Novel Coronavirus-Infected Pneumonia. N. Engl. J. Med. 2020, 382, 1199-1207. DOI: 10.1056/NEJMoa2001316.

43. Guan WJ, Ni ZY, Hu Y et al. Clinical characteristics of 2019 novel coronavirus infection in China. N. Engl. J. Med. 2020. DOI: 10.1056/NEJMoa2002032.

44. Lauer SA, Grantz KH, Bi Q, et al. The Incubation Period of Coronavirus Disease 2019 (COVID-19) From Publicly Reported Confirmed Cases: Estimation and Application. Ann. Intern. Med. 2020, [Epub ahead of print 10 March 2020]. doi: https://doi.org/10.7326/M20-0504.

45. Yang Y, Lu QB, Liu MJ, Wang YX, Zhang AR, Jalali N, et al. Epidemiological and clinical features of the 2019 novel coronavirus outbreak in China. medRxiv. Preprint posted February 21, 2020. doi: https://doi.org/10.1101/2020.02.10.20021675.

46. Lai CC, Shih TP, Ko WC, Tang HJ, Hsueh PR. Severe acute respiratory syndrome coronavirus 2 (SARS-CoV-2) and coronavirus disease-2019 (COVID-19): The epidemic and the challenges. Int. J. Antimicrob. Agents. 2020, 55(3), 105924. doi:10.1016/j.ijantimicag.2020.105924.

47. Chen N, Zhou M, Dong X et al. Epidemiological and clinical characteristics of 99 cases of 2019 novel coronavirus pneumonia in Wuhan, China: a descriptive study. Lancet. 2020, 395:507-13. doi:10.1016/ S01406736(20)30211- 7 .

48. Huang C, Wang Y, Li X et al. Clinical features of patients infected with 2019 novel coronavirus in Wuhan, China. Lancet. 2020, 395, 497-506. doi:10.1016/S0140-6736(20)30183-5.

49. Wang D, Hu B, Hu C, et al. Clinical Characteristics of 138 Hospitalized Patients With 2019 Novel Coronavirus-Infected Pneumonia in Wuhan, China [published online ahead of print, 2020 Feb 7]. JAMA. 2020, e201585. doi:10.1001/jama.2020.1585.

50. Chang D, Lin M, Wei L, et al. Epidemiologic and Clinical Characteristics of Novel Coronavirus Infections Involving 13 Patients Outside Wuhan, China [published online ahead of print, 2020 Feb 7]. JAMA. 2020, 323(11), 1092-1093. doi:10.1001/jama.2020.1623. 
51. Kanne JP. Chest CT findings in 2019 novel coronavirus (2019-nCoV) infections from Wuhan, China: key points for the radiologist. Radiology, 2020. [Epub ahead of print]. doi:10.1148/radiol.2020200241.

52. Song F, Shi N, Shan F, Zhang Z, Shen J, Lu H, et al. Emerging coronavirus 2019- nCoV pneumonia. Radiology. 2020 [Epub ahead of print]. doi:10.1148/ radiol.2020200274.

53. Yang $X, Y u ~ Y, X u ~ J$, et al. Clinical course and outcomes of critically ill patients with SARS-CoV-2 pneumonia in Wuhan, China: a single-centered, retrospective, observational study [published online ahead of print, 2020 Feb 24]. Lancet. Respir. Med. 2020. doi:10.1016/S2213-2600(20)30079-5.

54. Shi H, Han X, Jiang N, et al. Radiological findings from 81 patients with COVID-19 pneumonia in Wuhan, China: a descriptive study. Lancet. Infect. Dis. 2020, 20(4), 425-434. doi:10.1016/S1473-3099(20)30086-4.

55. Lee N, Hui D, Wu A, et al. A major outbreak of severe acute respiratory syndrome in Hong Kong. N. Engl. J. Med. 2003; 348: 1986-94.

56. Assiri A, Al-Tawfiq JA, Al-Rabeeah AA, et al. Epidemiological, demographic, and clinical characteristics of 47 cases of Middle East respiratory syndrome coronavirus disease from Saudi Arabia: a descriptive study. Lancet. Infect. Dis. 2013, 13, 752-61.

57. The Novel Coronavirus Pneumonia Emergency Response Epidemiology Team. The epidemiological characteristics of an outbreak of 2019 novel coronavirus diseases (COVID-19) in China. Zhonghua. Liu. Xing. Bing. Xue. Za. Zhi. 2020, 41(2), 145-151.

58. Badawi A, Ryoo SG. Prevalence of comorbidities in the Middle East respiratory syndrome coronavirus (MERS-CoV): a systematic review and meta-analysis. Int. J. Infect. Dis. 2016, 49, 129-33.

59. Channappanavar R, Fett C, Mack M, Ten Eyck PP, Meyerholz DK, Perlman S. Sex-based differences in susceptibility to severe acute respiratory syndrome coronavirus infection. J. Immunol. 2017, 198, 4046-53.

60. Wu Z, McGoogan JM. Characteristics of and Important Lessons From the Coronavirus Disease 2019 (COVID-19) Outbreak in China: Summary of a Report of 72,314 Cases From the Chinese Center for Disease Control and Prevention [published online ahead of print, 2020 Feb 24]. JAMA. 2020.10.1001/jama.2020.2648. doi:10.1001/jama.2020.2648.

61. You C, Deng Y, Hu W, Sun J, Lin Q, Zhou F, et al. Estimation of the Time-Varying Reproduction Number of 2019-nCoV Outbreak in China. medRxiv. Preprint posted February 17, 2020. doi: https://doi.org/10.1101/2020.02.08.20021253.

62. Jung S, Akhmetzhanov A, Hayashi K, et al. Real-Time Estimation of the Risk of Death from Novel Coronavirus (COVID-19) Infection: Inference Using Exported Cases, J. Clin. Med. 2020, 9(2), 523.

63. WHO. Clinical management of severe acute respiratory infection when novel coronavirus $(2019-\mathrm{nCoV})$ infection is suspected: interim guidance. Updated January 28, 2020. https://www.who.int/docs/default-source/coronaviruse/clinical-management-of-novel-cov.pdf

64. Muiller NL, Ooi GC, Khong PL, Nicolaou S. Severe acute respiratory syndrome: radiographic and CT findings. AJR. Am. J. Roentgenol. 2003, 181, 3-8.

65. Das KM, Lee EY, Enani MA, et al. CT correlation with outcomes in 15 patients with acute Middle East respiratory syndrome coronavirus. AJR. Am. J. Roentgenol. 2015, 204, 736-742.

66. Bernheim A, Mei X, Huang M, et al. Chest CT Findings in Coronavirus Disease-19 (COVID-19): Relationship to Duration of Infection. Radiology. 2020, 20, 200463.

67. CDC. Real-Time RT-PCR Panel for Detection 2019-Novel Coronavirus. Updated on 29 February 2020. https://www.cdc.gov/coronavirus/2019-ncov/downloads/rt-pcr-panel-for-detection-instructions.pdf.

68. Curetis Group Company Ares Genetics and BGI Group Collaborate to Offer Next-Generation Sequencing and PCR-based Coronavirus (2019-nCoV) Testing in Europe. Globe News Wire News Room. Updated on 
January 30, 2020. Archived from the original on January 31, 2020.

69. Yeo C, Kaushal S, Yeo D. Enteric involvement of coronaviruses: is faecal-oral transmission of SARS-CoV-2 possible? Lancet. Gastroenterol. Hepatol. 2020, 5(4), 335-337. doi:10.1016/S2468-1253(20)30048-0.

70. Holshue ML, DeBolt C, Lindquist S, et al. First Case of 2019 Novel Coronavirus in the United States. N. Engl. J. Med. 2020, 382(10), 929-936. doi:10.1056/NEJMoa2001191

71. Pan Y, Zhang D, Yang P, Poon LLM, Wang Q. Viral load of SARS-CoV-2 in clinical samples. Lancet Infect. Dis. 2020, 20(4), 411-412. doi:10.1016/S1473-3099(20)30113-4.

72. Oh MD, Park WB, Choe PG, et al. Viral load kinetics of MERS coronavirus infection. N. Engl. J. Med. 2016, 375(13), 1303-1305. doi:10.1056/NEJMc1511695.

73. Zhang Y, Chen C, Zhu S, Shu C, Wang D, Song J, et al. Isolation of 2019-nCoV from a Stool Specimen of a Laboratory-Confirmed Case of the Coronavirus Disease 2019 (COVID-19)[J]. China. CDC. Weekly. 2020, 2(8), 123-124.

74. Zumla A, Hui DS, Perlman S. Middle East respiratory syndrome. Lancet. 2015, 386(9997), 995-1007. doi: 10.1016/S0140-6736(15)60454-8.

75. Liu W, Tang F, Fontanet A, et al. Long-term SARS coronavirus excretion from patient cohort, China. Emerg. Infect. Dis. 2004, 10(10), 1841-3.

76. Normile D. Singapore claims first use of antibody test to track coronavirus infections. Updated on February 27, 2020. Science. doi:10.1126/science.abb4942.

77. WHO. Draft landscape of COVID-19 candidate vaccines, 11 April 2020. Updated on April 15, 2020. https://www.who.int/blueprint/priority-diseases/key-action/Novel_Coronavirus_Landscape_nCoV_11April202 0.PDF?ua=1.

78. Mark-M. Struck (1996). Vaccine R\&D success rates and development times. Nature Biotechnology. 1996, 14, 591-593.

79. Wang M, Cao R, Zhang L, et al. Remdesivir and chloroquine effectively inhibit the recently emerged novel coronavirus (2019-nCoV) in vitro. Cell Research. 2020, 10, 1-3; https://doi.org/10.1038/s41422-020-0282-0.

80. Lu H. Drug treatment options for the 2019-new coronavirus (2019-nCoV). Biosci. Trends. 2020. 14(1), 69-71. doi:10.5582/bst.2020.01020.

81. Xu Z, Shi L, Wang Y, et al. Pathological findings of COVID-19 associated with acute respiratory distress syndrome. Lancet. Respir. Med. 2020, S2213-2600(20)30076-X.

82. Jiang H, Deng H, Wang Y, Liu Z, Sun WM. The possibility of using Lopinave/Litonawe (LPV/r) as treatment for novel coronavirus 2019-nCov pneumonia: a quick systematic review based on earlier coronavirus clinical studies. Zhonghua. Jizhen. Yixue. Zazhi. 2020, 29(2), 182-186.

83. Gao J, Tian Z, Yang X. Breakthrough: Chloroquine phosphate has shown apparent efficacy in treatment of COVID-19 associated pneumonia in clinical studies. Biosci. Trends. 2020, 14(1), 72-73. doi:10.5582/bst.2020.01047. 84. Li G, De Clercq E. Therapeutic options for the 2019 novel coronavirus (2019-nCoV). Nat. Rev. Drug. Discov. 2020, 19(3), 149-150. doi:10.1038/d41573-020-00016-0.

85. Praveen Duddu. Coronavirus treatment: Vaccines/drugs in the pipeline for Covid-19. Updated on February 20, 2020. https://www.clinicaltrialsarena.com/analysis/coronavirus-mers-cov-drugs.

86. Harrison C. Coronavirus puts drug repurposing on the fast track. Nat. Biotechnol. 2020. doi:10.1038/d41587-020-00003-1.

87. Cao B, Wang Y, Wen D, et al. A Trial of Lopinavir-Ritonavir in Adults Hospitalized with Severe Covid-19. N. Engl. J. Med. 2020. doi:10.1056/NEJMoa2001282. 
88. CDC. How to Protect Yourself. Updated on March 3, 2020. https://www.cdc.gov/coronavirus/2019-ncov/about/prevention-treatment.html.

89. Wu Z, McGoogan JM. Characteristics of and Important Lessons From the Coronavirus Disease 2019 (COVID-19) Outbreak in China: Summary of a Report of 72314 Cases From the Chinese Center for Disease Control and Prevention. JAMA. 2020. doi:10.1001/jama.2020.2648.

90. Jin YH, Cai L, Cheng ZS, et al. A rapid advice guideline for the diagnosis and treatment of 2019 novel coronavirus (2019-nCoV) infected pneumonia (standard version). Mil. Med. Res. 2020, 7(1), 4. doi:10.1186/s40779-020-0233-6.

91. WHO. Home care for patients with suspected novel coronavirus (nCoV) infection presenting with mild symptoms and management of contacts. Updated on January 24, 2020. https://www.who.int/publications-detail/home-care-for-patients-with-suspected-novel-coronavirus-(ncov)-infe ction-presenting-with-mild- symptoms-and-management-of-contacts.

92. Wang Y, Lin LK. An advice guideline recommended by central south hospital for the suspected patients of novel coronavirus (2019-nCoV) infected pneumonia and their close contacts as at home quarantine. Updated on January 25, 2020. https://mp.weixin.qq.com/s/xFO10WAFB9OUnM7VN92R2w.

93. WHO. Infection prevention and control during health care when novel coronavirus (nCoV) infection is $\begin{array}{llllll}\text { suspected. } & \text { Updated } & \text { January } & 25, & 2020 . & \text { https:// }\end{array}$ www.who.int/publications-detail/infection-prevention-and-control-duringhealth-care-when-novel-coronavirus-(ncov)-infection-is-suspected-20200125.

94. McCloskeyB, HeymannDL. SARS to novel coronavirus: old lessons and new lessons. Epidemiol. Infect. 2020, 148:e22. doi:10.1017/ S0950268820000254.

95. Du Z, Wang L, Cauchemez S, et al. Risk for transportation of 2019 novel coronavirus disease from Wuhan to other cities in China. Emerg. Infect. Dis. 2020, 26(5). doi:10.3201/eid2605.200146.

96. Wilder-Smith A, Freedman DO. Isolation, quarantine, social distancing and community containment: pivotal role for old-style public health measures in the novel coronavirus (2019-nCoV) outbreak. J. Travel. Med. 2020, taaa020. doi:10. 1093/jtm/taaa020

97. Loh HHW, Tan Y, Taculod J et al. The Impact of High-Flow Nasal Cannula (HFNC) on Coughing Distance: Implications on Its Use During the Novel Coronavirus Disease Outbreak. Can. J. Anesth. 2020. doi:10.1007/s12630-020-01634-3.

98. Bourouiba L. Turbulent Gas Clouds and Respiratory Pathogen Emissions: Potential Implications for Reducing Transmission of COVID-19. JAMA. 2020. doi:10.1001/jama.2020.4756.

99. Rocklöv J, Sjödin H, Wilder-Smith A. COVID-19 outbreak on the Diamond Princess cruise ship: estimating the epidemic potential and effectiveness of public health countermeasures. J. Travel. Med. 2020, taaa030. doi:10.1093/jtm/taaa030

100. Frieden TR, Lee CT. Identifying and Interrupting Superspreading Events-Implications for Control of Severe Acute Respiratory Syndrome Coronavirus 2. Emerg. Infect. Dis. 2020;26(6):10.3201/eid2606.200495. doi:10.3201/eid2606.200495.

101. Nishiura H, Oshitani H, Kobayashi T, et al. Closed environments facilitate secondary transmission of coronavirus disease 2019 (COVID-19). medRxiV. Posted on March 03, 2020. doi: https://doi.org/10.1101/2020.02.28.20029272.

102. Tang X, Wu C, Li X et al. On the origin and continuing evolution of SARS-CoV-2. National Science Review. 2020, nwaa036, https://doi.org/10.1093/nsr/nwaa036. 
103. ECDC. Coronavirus disease 2019 (COVID-19) pandemic: increased transmission in the EU/EEA and the UK - seventh update. Updated on $25^{\text {th }}$ March 2020.

https://www.ecdc.europa.eu/sites/default/files/documents/covid-19-rapid-risk-assessment coronavirus-disease-2019-eighth-update-25-March-2020.pdf

104. WHO. Clinical trials on COVID-19. Updated on April 14.2020. https://www.who.int/emergencies/diseases/novel-coronavirus-2019/global-research-on-novel-coronavirus-2019 -ncov/solidarity-clinical-trial-for-covid-19-treatments

105. Duan K, Liu B, Li C et al. Effectiveness of convalescent plasma therapy in severe COVID-19 patients. PNAS. 2020. 10.1073/pnas.2004168117.

106. Ong SWX, Tan YK, Chia PY, et al. Air, Surface Environmental, and Personal Protective Equipment Contamination by Severe Acute Respiratory Syndrome Coronavirus 2 (SARS-CoV-2) From a Symptomatic Patient. JAMA, 2020. doi:10.1001/jama.2020.3227. 